ఠ

Open Access Full Text Article

CASE REPORT

\title{
Anti-tuberculosis medication-induced oculogyric crisis and the importance of proper history taking
}

This article was published in the following Dove Press journal:

International Medical Case Reports Journal

13 October 2017

Number of times this article has been viewed

\author{
Lin Ho Wong' \\ Endean $\operatorname{Tan}^{2}$ \\ 'University College Cork, Cork, \\ Ireland; ${ }^{2}$ Tan Tock Seng Hospital, \\ Singapore
}

\begin{abstract}
Oculogyric crisis (OGC), frequently caused by medications such as antiemetics, antidepressants, and anti-epileptics, is an acute dystonic reaction of the ocular muscles. It consists of wide-staring gaze (lasting variably from seconds to minutes), seizures, and a widely-opened mouth. To date, there have been no reports of anti-tuberculosis medications such as rifampicin, isoniazid, pyrazinamide or ethambutol inducing OGC. It is of utmost importance to recognize this adverse reaction, which could be incorrectly diagnosed as an anaphylactic-like reaction. In this paper, we highlight a case of a 66-year-old Indian man who presented with OGC induced by anti-tuberculosis medications which was initially suspected to be an anaphylactic reaction and was subsequently halted with the administration of diphenhydramine.
\end{abstract}

Keywords: oculogyric crisis, tuberculosis, rifampicin, isoniazid, ethambutol, adverse drug reaction

\section{Introduction}

Dystonia consists of intermittent contractions of muscles resulting in irregular and repetitive movements. It is frequently triggered or aggravated by any voluntary action. ${ }^{1}$ Oculogyric crisis (OGC), is a form of ocular dystonia frequently caused by medications such as antipsychotics which usually lasts from seconds to minutes. ${ }^{2}$ It usually presents with contraction of extraocular muscles resulting in a deviation of the eyes. ${ }^{3}$ The adverse side effects of anti-tuberculosis (anti-TB) medications are well-documented, including arthralgia, neurological disorders, hepatotoxicity, allergic reactions, and gastrointestinal disorders. ${ }^{4,5}$ To date, there have been no reports of rifampicin, isoniazid, ethambutol, and pyrazinamide (RHEZ) causing OGC. We report a case of a 66-year-old Indian man, admitted to the Department of General Medicine, Tan Tock Seng Hospital, Singapore, who developed acute OGC 30 minutes after ingesting RHEZ.

\section{Case report}

Written consent was obtained from the patient for the publication of his case and images. A 66-year-old Indian male patient presented to the Tuberculosis Control Unit after sudden onset of near syncope, nausea, diaphoresis, light-headedness, and a wide-staring gaze with upward and lateral deviation of eyes 30 minutes after consuming newly-prescribed RHEZ. These symptoms resolved on the administration of diphenhydramine $25 \mathrm{mg}$ intravenously at the Emergency Department. The patient was referred, initially, to the Department of Rheumatology, Allergy and Immunology based on the suspicion of a reaction to RHEZ. A diagnosis of anaphylaxis-like and possibly idiosyncratic reaction to rifampicin was made.
Correspondence: Lin Ho Wong

I Jalan Senang, S4I85II, Singapore

Tel +353834463304

Fax+65 63577588

Email113103563@umail.ucc.ie 
On further questioning by the primary team, the patient reported that while he was aware of his surroundings and was able to hear conversations around him, he felt "physical blocked" in that he was unable to respond with purposeful voluntary movements or speech; he additionally described abdominal discomfort and generalized weakness.

The patient had just been prescribed daily rifampicin $600 \mathrm{mg}$, isoniazid $300 \mathrm{mg}$, ethambutol $1.6 \mathrm{~g}$, pyrazinamide $1.75 \mathrm{~g}$ (i.e., standard RHEZ combination therapy for TB of uncertain origin and resistance, according to his weight of $98.3 \mathrm{~kg}$ ) and pyridoxine $10 \mathrm{mg}$ after increased nodular opacities in the left upper zone were observed on sequential chest X-rays (Figures 1 and 2), suggestive of granulomata. A small calcified pleural plaque was also noted. Blood cultures, sputum cultures, and Mycobacterium tuberculosis polymerase chain reaction were negative.

On his initial presentation after the near syncope, the patient's vitals were stable and physical examination, including neurological examination, did not reveal any conclusive findings. A full blood count, liver function test, thyroid function test, drug screen, troponin I, electrocardiogram (Figure 3), and a two-dimensional echocardiography were performed.

However, the diagnosis was subsequently changed to OGC based on the more complete history recorded. Another possible cause of OGC would include trauma. However, the patient did not suffer from any trauma recently.

\section{Discussion}

Acute dystonia is intermittent or sustained involuntary muscle contractions involving the face, neck, and other parts of the body ${ }^{6}$ OGC is a subset of acute dystonia which frequently affects the extraocular muscles resulting in spasmodic-like action. The most common cause includes medications such as metoclopramide, olanzapine, haloperidol, and carbamazepine. ${ }^{7,8}$ Certain recreational drugs such as cocaine have also been reported to cause OGC. ${ }^{9}$ Interestingly, until now there have been no reports of anti-TB medications causing OGC. In addition, OGC can occur in Wilson's disease, cystic glioma, and post-encephalitic parkinsonism. ${ }^{10-13}$

The pathophysiology of OGC is still uncertain, but it is believed to be caused by blockage of dopaminergic pathways centrally, which results in an upregulation of striatal acetylcholine. ${ }^{14}$ This in turn causes involuntary, irregular muscular contractions. A study done by Mendhekar et al. showed that, at low doses, amisulpride (100-300 mg/day) preferentially binds to $\mathrm{D} 2 / \mathrm{D} 3$ presynaptic receptors which subsequently increases dopaminergic transmission in the

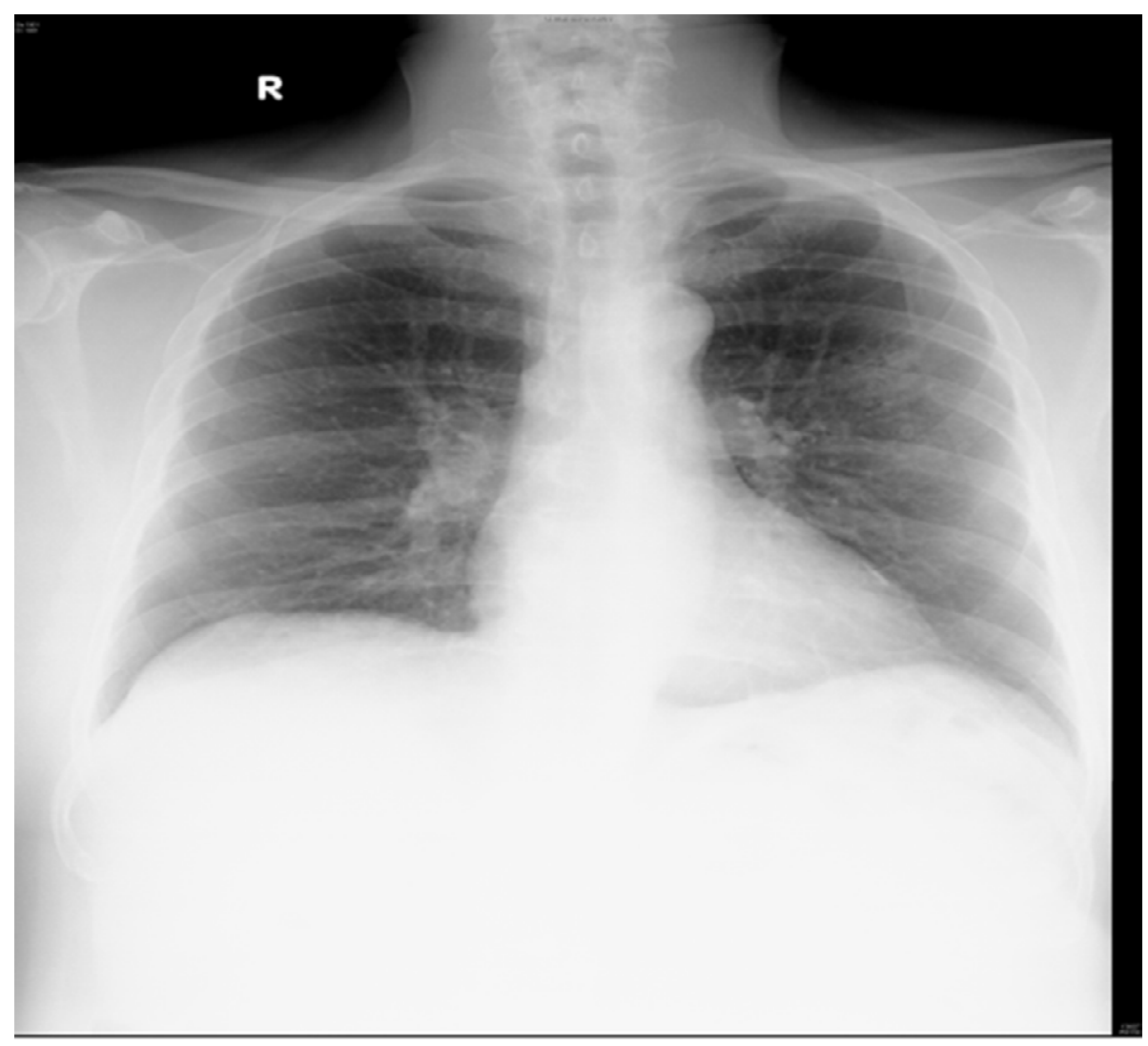

Figure I Nodular opacities in left upper zone periphery on chest X-ray (posteroanterior view). 


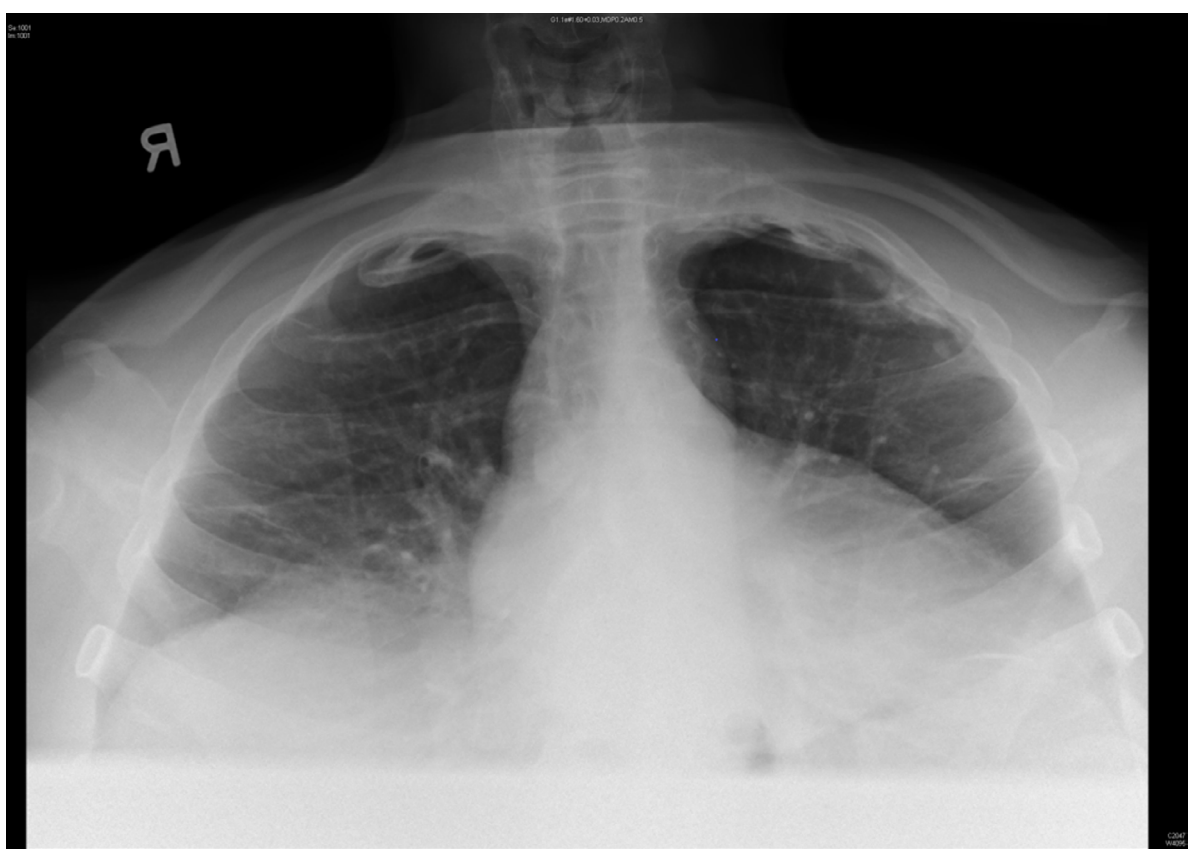

Figure 2 Nodular opacities in left upper zone periphery on chest X-ray (apical lordotic view).

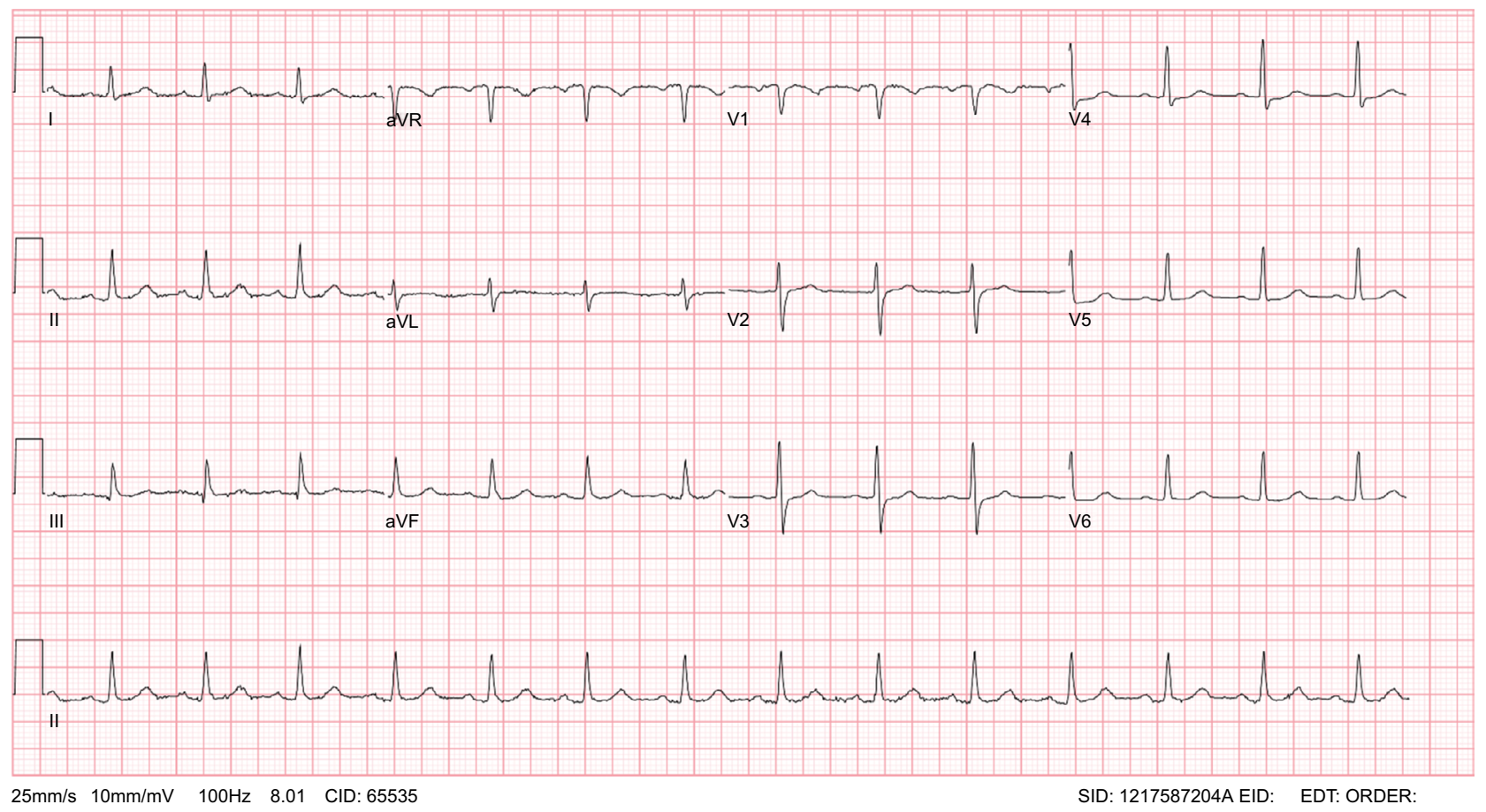

Figure 3 Electrocardiogram showing normal sinus rhythm.

prefrontal cortex. However, OGC occurred at a dose of 400$800 \mathrm{mg} /$ day where there is antagonism of the postsynaptic dopaminergic receptors. ${ }^{15}$ Shumy et al. reported a case of pyrazinamide-induced parkinsonism which could be linked to the dopaminergic antagonist effects of it. ${ }^{16}$ Similarly, the dopaminergic antagonist effects of pyrazinamide could have resulted in the OGC.
Reversal of OGC may be effected with the use of anti-cholinergic medications like promethazine or diphenhydramine. Diphenhydramine served both as a diagnostic test and therapeutic intervention in this 66-year-old gentleman.

In this case, the diagnosis was based on history and the resolution of symptoms with diphenhydramine. 


\section{Conclusion}

OGC is often a diagnosis that is overlooked because of an incomplete history, poor appreciation of the presentation of OGC, and a low index of suspicion in cases where the medication implicated is not often associated with such a reaction. In such cases, rather than assigning a label such as an "allergic" reaction, the history should be confirmed and if possible, a monitored drug challenge undertaken to ascertain the reaction provoked. Physicians should also be alert toward medications which are not known to cause OGC, but may also cause it.

\section{Disclosure}

The authors report no conflicts of interest in this work.

\section{References}

1. Albanese A, Bhatia K, Bressman SB, et al. Phenomenology and classification of dystonia: a consensus update. Mov Disord. 2013; 28(7):863-873.

2. Gardner DM, Abidi S, Ursuliak Z, Morrison J, Teehan MD, Tibbo PG. Incidence of oculogyric crisis and long-term outcomes with secondgeneration antipsychotics in a first-episode psychosis program. J Clin Psychopharmacol. 2015;35(6):715-718.
3. Robottom BJ, Factor SA, Weiner WJ. Movement disorders emergencies part 2: hyperkinetic disorders. Arch Neurol. 2011;68(6):719-724.

4. Singla R, Sharma SK, Mohan A, et al. Evaluation of risk factors for antituberculosis treatment induced hepatotoxicity. Indian J Med Res. 2010;132(7):81-86.

5. Volmink J, Garner P. Directly observed therapy for treating tuberculosis. Cochrane Database Syst Rev. 2007;(4):CD003343.

6. Munhoz RP, Moscovich M, Araujo PD, Teive HA. Movement disorders emergencies: a review. Arq Neuropsiquiatr. 2012;70(6):453-461.

7. Bateman DN, Rawlins MD, Simpson JM. Extrapyramidal reactions with metoclopramide. Br Med J (Clin Res Ed). 1985;291(6500):930-932.

8. Bhachech JT. Aripiprazole-induced oculogyric crisis (acute dystonia). J Pharmacol Pharmacother. 2012;3(3):279-281.

9. van Harten PN, Hoek HW, Kahn RS. Fortnightly review: acute dystonia induced by drug treatment. BMJ. 1999;319(7210):623-626.

10. Onuaguluchi G. Crises in post-encephalitic parkinsonism. Brain. 1961;84:395-414

11. Matsumura K, Sakuta M. Oculogyric crisis in acute herpetic brainstem encephalitis. J Neurol Neurosurg Psychiatry. 1987;50(3):365-366.

12. Lee MS, Kim YD, Lyoo CH. Oculogyric crisis as an initial manifestation of Wilson's disease. Neurology. 1999;52(8):1714-1715.

13. Stechison MT. Cystic glioma with positional oculogyric crisis. J Neurosurg. 1989;71(6):955-957.

14. Blanchet PJ. Antipsychotic drug-induced movement disorders. Can J Neurol Sci. 2003;30 Suppl 1:S101-S107.

15. Mendhekar DN Lohia D, Kateria P. Tardive oculogyric crisis associated with amisulpride monotherapy. J Postgrad Med. 2010;56(4):305-306.

16. Shumy F, Anam A, Chowdhury M, Shazzad M. Pyrazinamide Induced Parkinsonism. Journal Of Medicine. 2017:18(1):44-46.
International Medical Case Reports Journal

\section{Publish your work in this journal}

The International Medical Case Reports Journal is an international, peer-reviewed open-access journal publishing original case reports from all medical specialties. Previously unpublished medical posters are also accepted relating to any area of clinical or preclinical science. Submissions should not normally exceed 2,000 words or

\section{Dovepress}

4 published pages including figures, diagrams and references. The manuscript management system is completely online and includes a very quick and fair peer-review system, which is all easy to use. Visit http://www.dovepress.com/testimonials.php to read real quotes from published authors. 